\title{
Atopic Dermatitis in Psychoanalytic Psychotherapy - A Psychobiological Case Study
}

\section{Atopische Dermatitis in psychoanalytischer Psychotherapie - Eine psychobiologische Fallstudie}
B. Brosig ${ }^{a}$ J . Kupfer ${ }^{b}$
B. Köhnlein ${ }^{a}$
V. Niemeierc
U. Gieler

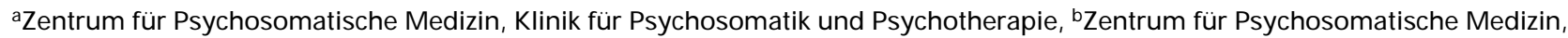
Abteilung für Medizinische Psychologie und CZentrum für Dermatologie und Andrologie, Universität Gießen

\section{Key Words}

Time series analysis - Psychoneuroimmunology .

Psychosomatics · Psychoanalysis · Atopic dermatitis

\section{Summary}

Presented is the case of a young woman suffering from atopic dermatitis since she started her career as a nurse specialized in child care. The descriptive approach to psychoanalytic treatment is paralleled by psychobiological process parameters, cortisol as well as IgA in saliva. The time series were analyzed by Granger tests and showed that depressive episodes triggered skin symptoms. The single-case analysis displays possibilities of data-based psychoanalytic casework.

\section{Introduction}

A topic dermatitis (synonyms endogenous eczema, atopic eczema, neurodermatitis Pruritus B esnier) belongs to the skin conditions most often discussed in public as 'psychosomatic'. The enormous rise in incidence has contributed to public interest in this puzzling disease, whose underlying basic defect is still unknown. In the early forties, A lexander [1] described atopic dermatitis as 'psychosomatic', thereby starting a discussion in which the skin condition became paradigmatic for psychosomatic thinking. U sing atopic dermatitis as his example, Schur [25] has developed the idea of a structural regression

\section{Schlüsselwörter \\ Zeitreihenanalyse - Psychoneuroimmunologie · \\ Psychosomatik · Psychoanalyse · Atopische Dermatitis}

\section{Zusammenfassung}

Vorgestellt wird die psychoanalytisch-psychosomatische Behandlung einer depressiven jungen Frau, die seit inrem Berufsstart als Kinderkrankenschwester an Atopischer Dermatitis litt. Die deskriptiv-psychoanalytische Prozeßformulierung wird dabei parallelisiert durch psychobiologische Prozeßparameter, Cortisol und IgA im Speichel. Die Zeitreihen wurden mittels Granger-Test auf kausale Zusammenhänge geprüft: Depressive Episoden triggerten die Hauterscheinungen. Die Einzelfallanalyse zeigt Möglichkeiten der datengestütten analytischen Kasuistik auf. from neurotic to psychosomatic symptoms: anxiety expresses itself as itching for purposes of psychic defense.

Spitz [27] and M arty [20-22] have closely investigated the interplay between the 'allergic' subject and significant others, delineating 'specific' patterns of object relations. E ven though aspects of these findings have been relativized by subsequent research, the originality of these psychosomatic formulations, creating a 'medicine of close relationships', has inspired further research in the field and has recently been supported even by psychoimmunological findings.

A Ithough psychoanalytic case reports have contributed to the standing of atopic dermatitis as the classic psychosomat-

\begin{tabular}{ll}
\hline KARGER & ○ 1999 S. K arger G mbH , Freiburg \\
Fax +49 761 452 07 14 & A ccessible online at: \\
$\begin{array}{l}\text { E-mail kargergmbh@aol.com } \\
\text { www.karger.com }\end{array}$ & http://B ioM edN et.com/karger
\end{tabular}


ic condition, few case studies have been paralleled by a systematic, data-based evaluation of the ongoing treatment process.

U sing time series analyses in a field setting [15], the present study has demonstrated that skin symptomatology in atopic eczema patients is triggered by 'daily hassles', depressive moods, and states of anxiety. In a case of urticaria, we tried to show how physical complaints, psychobiological markers such as salivary cortisol and secretory IgA, and skin symptoms interact with psychodynamic changes within the course of psychotherapy, which was realized in a ward setting in accordance with the therapeutic concept constituting the frame of this case presentation [3]. In line with the method of the sociological case study, by starting with a single case we endeavored to describe 'individual patterns of psychosomatic reagibility'; the individual case may, in the following, be used to 'show' (sensu Wittgenstein) how these bio-psycho-social signs [30] function and interact with each other. In contrast to mere case descriptions in the tradition of psychoanalytic case vignettes, we thus present 'objective' data material as a means of alternative process formulation. These data were more closely related to bodily changes than in descriptive formulations. They were also more evident and accessible without much interpretative effort. They even allow for alternative hypotheses and are, at the same time, 'signs' in the sense of private sense data, as indicated above.

If, in the following, a case of inpatient treatment is presented, and if, subsequently, time series analyses of psychological, behavioral, endocrinal and immunological data are utilized in connection with the psychoanalytical interpretation of such a case, this should not be taken to mean that the one procedure is being used to 'explain' the other. The time series data, in our understanding, are extensions of the clinical material and vice versa: our data derive from various system levels: interactional, psychological, and physiological. For the purposes of the study reported here, we have used the following sources and variables:

1. texts derived from clinical observation and submitted to psychoanalytical interpretation;

2. data drawn from psychological tests detailing the patient's psychic self-evaluation, e.g., moods (mood questionnaire by $\mathrm{H}$ echeltjen and Mertesdorf [10]); variables were $\mathrm{De}$ pression, A ctivation, A ggressivity.

3. behavioral data documenting the area of affected skin and skin-related features (e.g., scratching and itching sensations); variable A ffected Skin

4. endocrinological data, such as the concentration of cortisol and secretory rate of immunoglobulin A (IgA) in saliva (samples were drawn twice daily throughout the psychotherapeutic process for the technique of determination and their psychobiological relevance, see [6, 11, 12, 16-19]; variables were Cortisol and IgA. The data have been analyzed in depth (ARIMA methodology) from a perspective of medical psychology by Kupfer [19].

\section{Patient and Methods}

\section{Ward Setting}

We choose to call our therapeutic procedure a psychoanalytical one because we have been guided in our conceptualization of the clinical work by the realization and maintenance of psychoanalytical essentials. Patients were selected after a set of two psychodynamic interviews in which the ward-team participated. A team of two therapists headed the ward-team and the group therapy sessions, thus affording projection surfaces for the parental imagines. Clinical visits by superiors were reduced to a minimum, in order not to disturb the process of transference. Instead, the ward-team was supervised, the supervision placing particular emphasis on the detection of unconscious conflicts within patients projected onto team members (parallel process, see [31]).

\section{Patient}

The female patient appeared in summer 1992 complaining of atopic dermatitis and symptoms of serious depression. She said that she was very unhappy with herself for not being more successful in her academic studies, and that she was afraid of causing her parents shame and worry on that account. O utpatient psychotherapy was initially recommended, and the patient began a therapy. H owever, when her thoughts turned increasingly to suicide and she grew less able to deal with everyday life, the consulting psychotherapist advised her, in view of her critical situation, to avail herself of inpatient treatment. A ccording to the patient, she felt that she was in good hands with her therapist (a stable relationship had been established and her self-doubt and sense of inadequacy were already diminishing), but that outpatient therapy, in her judgment, wasn't going to be enough to get her 'out of the hole' she found herself in.

R elevant biographical data include the following: the patient, of a somewhat exotic, dark-complexioned outward appearance, is the third daughter of four children. Her father, born in Indochina in 1930, mentioned during a family conversation that he came from a well-off and respected family. A Ithough the patient's father, in danger because of political conflicts, had to leave his homeland, his alert intelligence and boundless energy enabled him to be so successful academically that he was awarded a grant to study in Paris. It was there that he met the patient's mother; born in Germany in 1937, she was visiting the French capital after completing her training as a businesswoman specializing in foreign trade. The patient describes her as being an enterprising, vital and active woman, bursting with energy. A fter they have moved to G ermany, the couple found it difficult to come to rights, and the patient's young I ndonesian father, with all his intellectual training, was forced to make his living as a foreign language teacher. 
A first daughter died in her first year and two miscarriages followed. Finally her mother gave birth to a second child, her 'favorite daughter'. A s a successful journalist, she is regarded as the 'model daughter' of the family. A 2 years younger sister, she says, is very close to her father, as she too is employed in the management department of a large computer company and, cosmopolitan and multilingual, is at home anywhere in the world.

The patient herself, born (she says) 'prematurely' in Stuttgart, developed eczema as an infant. The atopic dermatitis condition, from which the patient still currently suffers, was first diagnosed when she was three years old. A t school, the patient experienced her exotic and exquisitely fine appearance as a burdensome stigma. She felt she was the outsider in all of her school classes. H er education took her from G ermany to $\mathrm{E}$ ngland and France. She recounted vividly how she was branded as a German and a Nazi when she was abroad, and how she frequently got involved in violent arguments with her classmates. However, her atopic dermatitis almost completely healed up during this period. A fter the failure of a 'premature' marriage, she embarked on training as a nurse in a children's hospital, but had to discontinue this because of her dermatitis. She then underwent disability re-training, followed by further medical training, which the patient again had to terminate because of a resurgence of atopic dermatitis and depressive anxiety.

A t admission, the patient exhibited an unusual skin condition typical of atopic dermatitis, with scratches especially on her elbows, above her wrists, and on her neck. I tching salve was applied along with cleansing lotion. $L$ ab tests could determine no increase in the IgE level.

\section{Results}

Initial Phase of I npatient Therapy: Re-Staging of an E arly Traumatic E pisode

The early phase of treatment was characterized by the patient's uncertainty in locating in a ward setting the reassuring, stabilizing environment required for the further working-out and resolution of her inner conflicts. The patient re-lived a climate of uncertainty and anxiety which we were subsequently able to relate to the biography of her early childhood.

A fter seeming to have made a good 'arrival' in the ward, she quickly came under emotional pressure. $\mathrm{H}$ er defenses 'crumbled' more and more, and depressive thoughts occupied her increasingly. Moving her to the psychiatric clinic was considered. A $n$ argument arose within the team about whether the patient could be effectively treated by psychotherapeutic means, and a split opened up. The 'psychiatric party' pressed for moving the patient to a closed ward, while the 'analytical party' argued for holding out, in order to be able to convey to the patient that we were in a position to re-integrate her state of inward chaos. On the first weekend after admission, the patient's emotional condition peaked in a concentration of depressive thoughts, with the result that immediate transfer to a psychiatric ward was effected on account of the suicidal tendencies remarked.

The patient appeared grateful, after overcoming her crisis, to be able to return to us. As she gradually realized that we cared about her welfare to the point of putting her in what she had hitherto termed the 'wrong procedure' of psychiatric treatment in order to provide her with optimum care, she gained more confidence in our ward. In a parallel development, the dissenting 'psychiatric' and 'psychoanalytical' parties made up their differences.

A fter the acute psychic symptoms appeared to be overcome, the patient's atopic dermatitis at first worsened considerably. The psychic concentration on itching and scratching, paradoxically enough, seemed to stabilize the patient emotionally, so that her deep depressive fantasies ('I'm only causing my parents trouble, it would be better if I could spare them my existence') lessened. O ur team discussions produced consensus on the possibility of an 'alternation' between allergy and psychosis [7]. The team was reminded of the subtle description provided by A nzieu [2] concerning the formulation of the 'epidermal ego'. A member of our therapy team who had studied with A nzieu offered a convincing portrayal of his personality and mentality. We thus endeavored to view the neurodermatitic symptoms as something progressive, as a generative ego-achievement [23].

We accordingly began to concern ourselves even more intensively with the patient; the highly aggressive content of her thoughts and her suicidal tendencies were gradually 'detoxified' as the ward team worked its way through counter-transference via introspection; despite the patient's many difficulties in dealing with her life, we began to habituate her to the requirements of the therapeutic technique, with due consideration of the fragility of her defense structures. The patient was now increasingly able to see via introspection what was happening with her and thus to deal with her condition in a more mature fashion. A s a 'gift' to us, or an expression of successful 'containment', in the third week of treatment she recounted a dream in the course of group therapy:

\section{A First D ream}

'I find myself at home with my mother, where my grandmother is living. It is wartime. Fighter planes are dropping incendiary bombs on my mother's parental home, in which we have been living for a long time. I look all about me through the attic window and can see only destroyed houses. Then the picture changes, and I suddenly find myself in A merica. I am strolling through the downtown area of an A merican city, probably A tlanta, Georgia. I look in the window of a book shop and discover that my father has written a book; this fact 


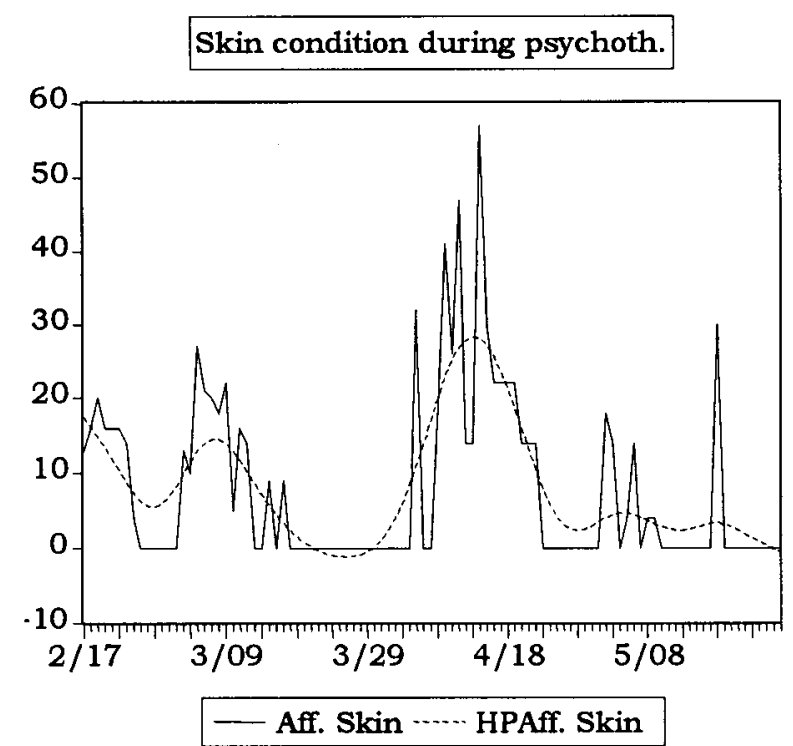

Fig. 1. X-axis: time (month/day); $y$-axis: value of the variable 'A ff. Skin' (standardized questionnaire); solid line: course of the variable 'A ff. Skin'; dotted line: curve (smoothed via filtering) showing trend.

delights me. $\mathrm{H}$ is book is not published in G erman. I can't understand it, as it's written in a foreign language.'

The patient had that dream on the weekend: i.e., while the therapy team was away, and reported in the group therapy session on the following M onday. I mention this because this period of weekend leave, in contrast to the events surrounding the leave period of the first weekend, was experienced as less dramatic and catastrophic.

\section{The $D$ ream Content}

We think that the patient's experiences are reflected in this situation, without these experiences having to be acted out on the stage of the ward. In regard to the associations with the dream content, which in the first instance have to do with the second part of the dream, the patient recalls that her father, with all his exoticism, was a mystery to her. A s he only revealed very little about his private life, the patient was left in a state of permanent curiosity and with a desire to learn more about his life history.

\section{The Initial D ream Sequence}

A t first, however, little occurred to the patient in connection with this sequence. She remembered only that her mother was recently very aggressive but without really knowing why. It is our opinion, formed during the team conferences, that the transference sessions on the ward clearly show that the first sequence represents the patient's psychic translation of how hard it was for her at first to find on the ward the reassuring, stabilizing milieu that would have helped her to begin treatment in the sense of psychic processing beyond the level of mere action; it was, rather, the case that she experienced her home ( $=$ the ward) as a threatened and embattled place.

We believe that the second part of the dream contains a transferential aspect: it is clearly the therapist who studied in A tlanta and who, in the form of the father, turns up in the dream. The patient is curious about him but cannot understand him. This dream sequence reveals how transferential features and biographical material are telescopically overlaid. In the patient's interest in the male therapist during the processing of maternal aspects of transference on our ward, we detect elements of the aforementioned triangular structure of the ward setting with its balance between maternal and paternal transference.

The middle phase of therapy was characterized by precisely this alternation between depressive despair, somatization with reactivation of the neurodermatitic condition, and remembering and working-through (fig. 1).

\section{The $L$ ast Stage of Treatment}

It became clearer that the patient's massive attacks of depression and her suicidal self-hatred not only served to stabilize a fragile sense of self but also functioned to prevent her from seeing herself as an attractive, exotically pretty young woman. It was, rather, the case that she frequently 'did herself down' and seemed to summon up the problem of her sense of selfworth as a defense whenever drive conflicts threatened. When this was drawn to her attention, a further dream occurred, one which she recounted in a group session two weeks before she was released from the ward:

\section{D ream 2}

'I am walking through the town and a black man is running behind me: I am afraid that he might touch me, for I know that I would then turn black as well. The black color is infectious. I am terribly afraid that I could be afflicted with this infection.' The picture then changes: 'I see M arilyn M onroe taking several tablets and destroying herself. Marilyn wants to walk up a staircase, but her mother swears at her and pushes her down the stairs. Her mother reprimands her for taking so many tablets.'

The patient woke up and lay alertly still for a long time. A fter about a quarter of an hour she then ran to M r. M., her night nurse, in order to get a 'sedative', with which request he complied. In the group session, associations were gathered in response to the dream, all of which reflected sexual experiences. It became clear that the patient gladly saw herself represented in M arilyn M onroe, the 'dream woman' - a dream figure who is the primary image of male desire. This can be seen as involving her in competition with her mother: a conflict which the patient seemed to be afraid of.

D oesn't the ascent of the staircase have something to do with drives and instincts? Scenes were evoked in group discussion 
in which cats 'on heat' darted up and down stairs, pursued by a tomcat. I sn't it the case that M r. M ., the night nurse, was an attractive man? Did the patient really only want a sedative tablet from him? The color black, too, would appear to possess the quality of arousal. I t recalls the father, who has a dark complexion and who gave the patient 'half' of his coloring (infecting her, as it were). The fantasy of infection was linked to the sexually transmitted disease of AIDS, a topic that preoccupied the group. They recalled that memories of the father surfaced in the group sessions prior to the dream experience, and that these memories were of someone whose behavior was often uncontrolled and impulsive; he would react in the presence of the patient with barely controlled impulsiveness. Once, the patient recalled, he tore open her blouse in a temper and, embarrassed and aroused, then ran out of the room. In the team sessions, the clear formal resemblance between the first and second reported dreams was also discussed, along with the sharp division or split in these dreams between paternal and maternal images. O ne part of the dream potential seemed to be devoted to separating the parents from each other in order not to have to perceive them as a couple. In its formal structure here, the dream seems to us to illustrate a defense against the oedipal scene. In the patient's account, however, the second dream has a generally milder effect and the dream ductus has a generally more narrative configuration, which corresponds to our impression that the patient, towards the end of the course of treatment, was reacting in a psychically altered mode in which she was able to represent her impulses in sublimated form and to employ more mature symbolic registers in order to express her inner drama on the stage of her dreams.

\section{Concluding Remarks on the Bio-P sycho-Social Circle}

In the case of this patient, we thus have a young woman who is suffering from the burden of an early deficit, characterized by an alternation between, on the one hand, a dynamic characterized by splitting with projection (i.e., early oral defense formations), as described especially by Kernberg $[13,14]$ for borderline inpatients, and, on the other, psychosomatic features which, in this dynamic alternation (also cf., in this connection [8]), are the realization of a progressive condition. $M$ arkedly depressive symptoms involving notions about one's own worthlessness bordering at times on delusional conviction thus alternate with symptoms of psychosomatic illness (atopic dermatitis) which are accompanied by acts of auto-aggression (scratching). When the patient feels pain or itching on her skin, she experiences this in a coherent way and may additionally (via scratching) be relieved by her attacks from the rigorously depressive conditioning of her superego.

Because of the patient's great resilience to suffering and her high intelligence, and not least because of the attractive exoticism of her outward appearance, she constantly managed to represent new parental images and thus capture the interest of our therapy team, implicating them in her experience of the critical climaxes of her inward drama. The treatment made it quite clear that the young patient found it difficult to amalgamate the various representations of parental images and their attached experiences, to represent these in trianguIar space, and thereby to attain a coherent experience of Self. Her ego or Self thus appears to be torn between a maternal, locally rooted, Swabian core of identity and the cosmopolitan identity of her polyglot father, a leading businessman, at home in the wide wide world. She thus appeared to us as an exotic woman with a Swabian accent.

Conversely, as the dream images show, her attempts to evade superimposition of her parents' imagines often seemed quite energetic, so that one part of her oedipal dramatism would appear to reside precisely in separating them (to express it in Kleinian terms) in order to prevent a triangulation which would, after all, imply an admission that the parents as a couple maintained their relationship by excluding the child.

On the stage of the ward, the process of therapy registered important elements of the patient's inner dynamic: D uring the initial phase the patient seemed exposed; her defenses crumbled; ego-disorganization occurred along with an overpowering sense of anxiety which later, with the formation of psychosomatic symptoms, gradually ebbed away. Transference seemed to show that her expectation of the therapists was to be 'carried and held'. A s in a repetition compulsion, however, we at first behaved (via projective identification) as overtaxed, quarreling parents. B ut a gradual working-through of counter-transference experiences then permitted a better reintegration of the patient's chaotic experiential modes, and she managed to bring herself to stay in the ward and go through the process of therapy.

Once a solid foundation was established for the therapeutic cooperation required, the patient felt better able to try and come to terms with her instinctive desires and to examine these in the light of their oedipal dynamic. During transference, father and therapist were projected as cautiously curious - indeed, as secretly desired, until the mother intervened like a stroke of lightning (as the patient intimated in an image that arose during inpatient treatment). It is the violence and impulsiveness of her superego that are expressed in the form of lightning. D uring counter-transference, we were all too easily persuaded, thanks to the patient's childlike urge to 'hold tight', not to pay sufficient attention to the role played by her sexual impulses. Only by working through the patient's counter-transferential defenses in connection with the more mature sexual side of her personality was the young woman finally able to see herself more clearly in terms of her femininity and to accept herself as attractive. When the changes in salivary cortisol (measured in parallel with the therapy) are also considered, then the patient's emotive fluctuations during the course of therapy become quite comprehensible (fig. 2). 


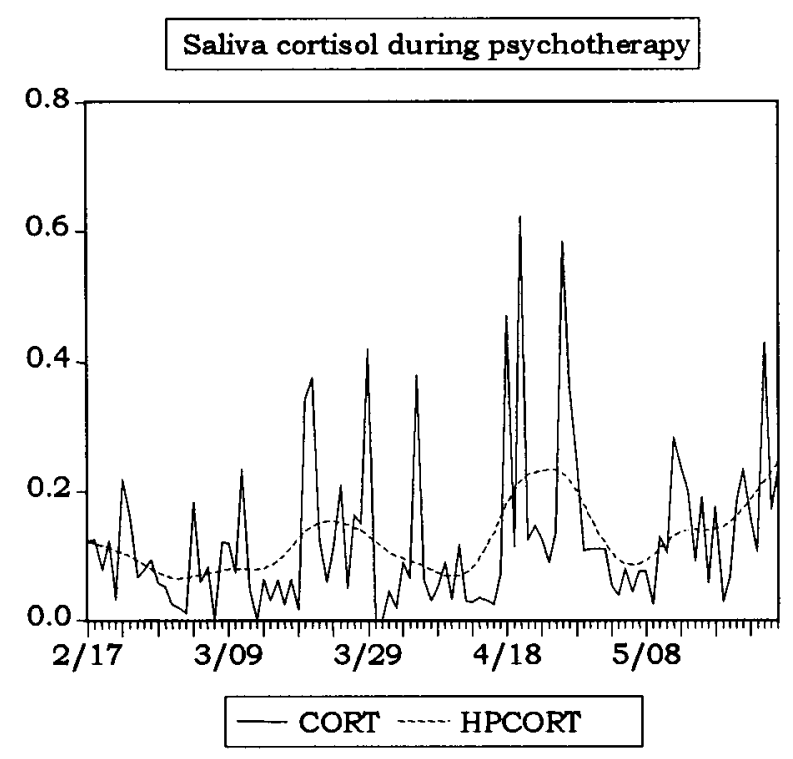

Fig. 2. X-axis: time (month/day); $y$-axis: value of the variable 'salvia cortisol' ( $\mu \mathrm{g} / \mathrm{dl})$; solid line: original data from the time series analysis of cortisol; dotted line: curve (smoothed via filtering) showing trend.

On the level of immunological defense as measured by saliva IgA, the therapy process shows, concurrently with this, that the parameter underwent 'resonance' (fig. 3).

A t the end of treatment, the patient generally appeared to be reconciled to her fate, as well as to her inner identifications and parental object-images, and it appeared that a foundation had been laid for a better integration of her sexual and aggressive impulses and thus for the ensuring of a more enjoyable and successful life in the future. $\mathrm{O}$ leaving the ward, the patient appeared prettier, more feminine, and more self-assured.

\section{Statistical Analysis of Time Series Data}

L ooking at correlations or temporal associations derived from a graph, our visual analysis does not necessarily allow to derive causal hypotheses in a meaningful sense of the word. The following statistical analysis, thus, focuses on the problem of (statistical) causation of two bivariate time series by using the Granger - approach [9], which studies the question whether the current values of a given variable y can be explained by past values of $y$ and then to see whether adding lagged values of an independent variable $x$ can improve the explanation. 0 ur null hypothesis is, that the pair of variables $x$ and $y$ are independent. A II time series were transformed by a HodrickPrescott filter, which allowed to stabilize the trend of the data. In table 1, it can be shown that:

- the area of affected skin is triggered by depressive moods and does, itself, causes changes in secretory I gA , saliva cortisol and activated mood.

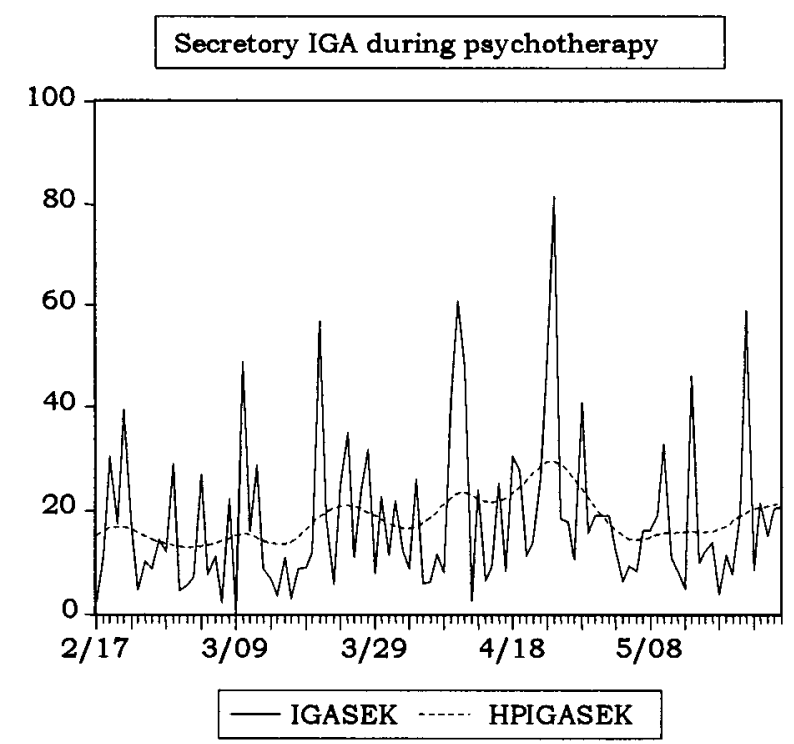

Fig. 3. X-axis: time (month/day); y-axis: value of the variable 'secretory IgA' ( $\mu \mathrm{g} / \mathrm{min})$; solid line: original data from the time series analysis of secretory IgA; dotted line: curve (smoothed via filtering) showing trend.

- aggressive moods result in changes of saliva cortisol, secretory IgA and also trigger changes in depressive moods.

A Il reported results are significant $(p<0.005)$.

\section{Discussion}

If one returns to the question of the dynamic function that can be assigned to the neurodermatitic condition within the therapeutic context, then the skin condition remarked during the process of therapy would appear primarily to have produced a stabilizing effect on the patient's sense of self; it was, furthermore, clear that these epidermal symptoms were of a defensive nature in the sense of representing a struggle against exhibitionistic desires on the genital level. The patient's atopic dermatitis can thus not be said to involve a single, one-dimensional psychodynamic, not even in terms of this being an individual case. The symptom, rather, encodes several conditions simultaneously, not unlike an archaic, polysemous sign or symbol.

It would be worth investigating, and describing, the question of whether the atopic dermatitis symptom, within the interactive network of affect, immune system and skin condition, might merely be an epiphenomenon of a generalized psychoneuro-endocrinological reaction on the part of a genetically predisposed individual. In such terms, the skin assumes, rather, the function of a 'mirror of the soul': i.e., can be understood as the projective surface of an underlying, simultaneous psychosomatic event and should thus not be conceptualized as the genuine 'expression' of an emotional conflict. A s earli- 


\section{References}

1 A lexander F: Psychosomatic M edicine. New York, Norton, 1990.

2 A nzieu D : L e M oi-peau. Paris, B ordes, 1985.

3 Brähler CH Brosig B Kupfer J, Brähler E : Health condition and psychoimmunological parameters in the therapy process of $U$ rticaria - a quantiative single case analysis. Psychother Psychosom M ed Psychol 1994;44:323-330.

4 B rosig B, Kupfer J, Brähler E : Neurodermitis und A sthma - ARIMA-Impact-A nalyse eines stationären Therapieverlaufs; in G ieler U, Stangier U, Brähler $E$ (eds): Hauterkrankungen in psychologischer Sicht. Jahrbuch der Medizinischen Psychologie 1993;9:164-179.

5 B rosig B., M öhring P, Kupfer J, B eckmann D: A combined clinical and psychobiological Study of Narcissism. Psychoanal Inq 1998;18:469-489.

6 Buske-K irschbaum A, Jobst S, Wustmann A, K irschbaum C, R auh W, H ellhammer D: A ttenuated Free Cortisol R esponse to Psychosocial Stress in Children with A topic Dermatitis. Psychosom Med 1997:59:419-426.

7 Freedman DX, R edlich FC, I gersheimer W W: Psychosis and allergy. Am J Psychiatry 1956;112: 873-877.

8 G ieler U, D etig-Kohler, C: Nähe und D istanz bei H autkranken. Psychotherapeut 1994;39:259-263.

9 G ranger CW: Investigating causal relationships by econometric models and cross-spectral methods. E conometrica 1969;37:424-438.

10 Hecheltjen KG, Mertesdorf $F$ : Entwicklung eines mehrdimensionalen Stimmungsfragebogens (M SF). G ruppendynamik 1973;2:110-112.

$11 \mathrm{Hennig} \mathrm{J:} \mathrm{Die} \mathrm{psychobiologische} \mathrm{Bedeutung} \mathrm{des}$ sekretorischen Immunglobulin A im Speichel. M ünster, Waxmann, 1994.
12 Henning J, Netter P: Local immunocompetence and salivary cortisol in confinement. A dv Space Biol Med 1996;5:115-132.

13 Kernberg 0 : Internal world and external reality. $O$ bject relation theory applied. New York, Jason A ronson, 1985.

14 Kernberg 0: Psychoanalytic object-relations theory, group process and administration: Toward an integrative theory of hospital treatment. A nnual Psychoanalysis 1973;1:363-388.

$15 \mathrm{~K}$ ing R M , Wilson G V: $\mathrm{U}$ se of a diary technique to investigate psychosomatic relations in atopic dermatitis. J Psychosom Res 1991;35: 697-706.

$16 \mathrm{~K}$ irschbaum C, H ellhammer DH: Salivary cortisol in psychoneuroendocrine research: R ecent development and applications. Psychoneuroendocrinology 1994;19:313-330.

17 Kugler J Hess M Haake D: Secretion of salivary immunoglobulin $\mathrm{A}$ in relation to age, saliva flow, mood states, secretion of albumin, cortisol, and catecholamines in saliva. J Clin Immunol 1992;12: 45-49.

18 Kugler J: Emotionale Befindlichkeit und Immunglobulin A im Speichel. Eine Literaturübersicht. Psychoth. Psychosom Med Psychol 1991;41:232242

19 Kupfer J: Eine psychoimmunologische Verlaufsstudie bei Patientinnen mit atopischer D ermatitis. U nveröff. D iss. G iessen, 1994.

20 M arty $P$, de $M$ ' $U$ zan $M$, D avid C: L' investigation psychosomatique. Presses universitaires, Paris, 1963.

21 Marty P: La relation objectale allergique. R evue Francaise Psychoanalytique 1958;22:5-35.

$22 \mathrm{M}$ arty P: N otes cliniques et hypotheses a propos de
I' economie de I' allergie. R evue Francaise Psychoanalytique 1969;33:243-253.

23 Overbeck G: Das Psychosomatische Symptom Defizienzerscheinung oder generative Ich-Leistung? Psyche 1977;31:333-354.

24 R eiser M F : M ind, Brain, B ody: Toward a Convergence of Psychoanalyses and Neurobiology. New York, B asic B ooks, 1984.

25 Schur M: Comments on the metapsychology of somatization. Psychoanal Stud Child 1955;10:119 164.

26 Sifneos PE : A ffect, emotional conflict, and deficit A n overview. Psychother Psychosom 1991;56:116122

27 Spitz, R: G enèse des premières relations objectales. R ev Franc de Psychanalyse Presses U niversitaires de France, 1954

28 Stephanos S: A concept of analytical treatment for patients with psychosomatic disorders. Report on the psychosomatic phenomenon and its consequences for therapy. Psychother Psychosom 1975 26:178-187.

29 Vingerhoets A J, A ssies ] : Psychoneuroendocrinology of Stress and E motions: Issues for Future R esearch. Psychother Psychosom 1991;55:69-75.

30 von U exküll T: Wissenschaftstheorie: $\mathrm{E}$ in bio-psycho-soziales M odell; in von U exküll T et al. (H rsg) Psychosomatische Medizin. München, U rban Schwarzenberg, 1996.

31 Woidera R, B rosig B: Teamprocesses in the course of inpatient-treatment of narcissistic and borderline-patients. (English abstract) Gruppenpsychother G ruppendyn 1991;27:332-342. 